\title{
First record of Schizopyga Gravenhorst (Hymenoptera, Ichneumonidae, Pimplinae) from Brazil and a description of a new species
}

\author{
Loffredo, APS.* and Penteado-Dias, AM.* \\ Departamento de Ecologia e Biologia Evolutiva, Universidade Federal de São Carlos - UFSCar, \\ Rodovia Washington Luís, Km 235, CEP 13565-905, São Carlos, SP, Brazil \\ *e-mail: ap_loffredo@yahoo.com.br, angelica@ufscar.br
}

Received February 29, 2008 - Accepted March 10, 2008 - Distributed May 31, 2008

(With 4 figures)

\section{Introduction}

Studying material proceeding from samplings carried out in the Southeast of Brazil, we have founded two specimens of the genus Schizopyga (Hymenoptera, Ichneumonidae Pimplinae). Pertaining to the Polysphincta genus-group, it includes the koinobiont ectoparasitoid species of spiders. All host records for this genus are of species attacking Clubionidae and Miturgidae spiders (Gauld and Dubois, 2006).

Two female specimens were obtained from the Campos do Jordão region, São Paulo State, Brazil, at $22^{\circ} 44^{\prime} \mathrm{S}$ and $45^{\circ} 30^{\prime} \mathrm{W}$, at 600 and $1200 \mathrm{~m}$, respectively using Malaise traps from 27.IX to 12.X.2002.
The specimens were deposited in the collection of the Universidade Federal de São Carlos, Departamento de Ecologia e Biologia Evolutiva, São Carlos, São Paulo, Brazil (DCBU). This is the first time that this genus has been illustrated visually in a figure. The subfamily Pimplinae and the genus Schizopyga (= Dreisbachia) were recognized using Gauld (1991).

\subsection{Schizopyga moreirai sp. nov. Loffredo and} Penteado-Dias (Figures 1-4)

Material: Holotype, + (DCBU), "Brazil, SP, Campos do Jordão, 27.IX to 12.X.2002, 600 m altitude,
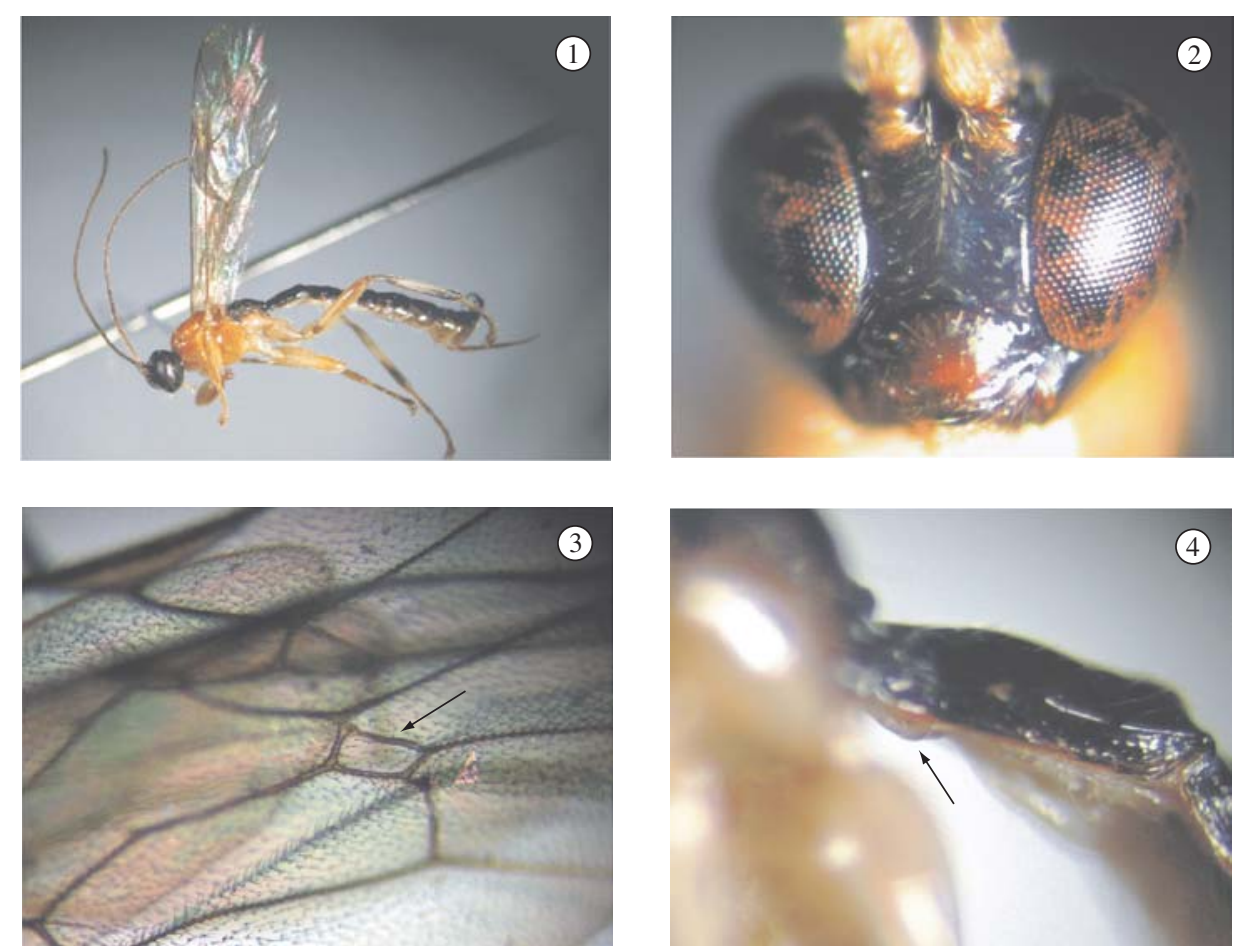

Figures 1-4. Schizopyga moreirai sp. nov. (female): 1) habitus; 2) eyes surface; 3) fore wing venation; 4) sternite I. 
Malaise trap, S.A.G. Gomes and team col." ; paratype $q$ (DCBU), the same as holotype, $1200 \mathrm{~m}$ altitude.

Female (Figure 1): eye surface more or less glabrous (Figure 2), face polished, with fine punctures and long hairs, the width being 1.2 times the length. The head in the dorsal view with long genae, ocelli moderately large, separated from the eye about 1.3 times its own maximum diameter. Mesosoma smooth, polished almost all glabrous. Mesoscutum hirsute; scuto-scutellar groove with a large pit at either end; scutellum convex, no carinate laterally; mesopleuron dorsally hirsute, ventrally finely punctuate; metapleuron weakly convex. Propodeum mediodorsally smooth and polished, laterally with sparse punctures bearing long hairs. Forewing $6.0 \mathrm{~mm}$ long with $3 \mathrm{rs}-\mathrm{m}$ vein present (Figure 3), cu-a vein distal to base of Rs\&M vein by 0.2 times its own length. Metasoma with tergites highly polished; tergite I weakly broadened posteriorly, 1.8 times as long as wide, dorsally with lateromedian longitudinal carinae discernible on its basal 0.2 ; sternite I with a rounded protuberance near hind end (Figure 4); tergite II with anterior lateral corners costate rugose.

Head black, with palpi ivory; antennae light brown with scape and the pedicel yellowish. Mesosoma pale orange with all metapleuron, lower corner of mesopleuron, lower edge of pronotum and propleuron, upper hind corner of pronotum and tegula ivory. Propodeum and metasoma blackish. Legs ivory; first pair with tarsomeres infuscate; second pair with femur, tibia e tarsi infuscate, third pair with coxa ventrally, trochanter and trochantellus, external margin of femur, tibia ventrally, anteriorly and posteriorly and tarsi infuscate.

Schizopyga moreirai sp. nov. differs from S. avivae (Gauld, 1991) in having, as well as $S$. navajo (Townes, 1960), only a slight rounded protuberance on sternite I. It differs from $S$. navajo in having propleuron and metapleuron ivory and most of the pronotum pale orange, and as in the case of $S$. avivae more or less glabrous eyes.

Male: Unknown.

Etymology: This species is named in honour of our colleague Orlando Moreira Filho.

Acknowledgements - To CNPq (Conselho Nacional de Desenvolvimento Científico e Tecnológico) and FAPESP (Fundação de Amparo à Pesquisa do Estado de São Paulo, Programa Biota) for the financial support.

\section{References}

GAULD, ID., 1991. The Ichneumonidae of Costa Rica, 1. Memoirs of the American Entomological Institute, vol. 47, p. 1-589.

GAULD, ID. and DUBOIS, J., 2006. Phylogeny of the Polysphincta group of genera (Hymenoptera: Ichneumonidae; Pimplinae): a taxonomic revision of spider ectoparasitoids. The Royal Entomological Society, Systematic Entomology, vol. 31, no. 3, p. 529-564. 